\title{
CULTURAL CHANGE AND HUMAN BEHAVIOR: EVOLUTION OR DEVELOPMENT?*
}

\author{
Antonella Delle Fave (Italy)
}

Fausto Massimini (Italy)

\begin{abstract}
The study of cultures in today's world has become a major academic exercise. There are many challenges and problems for human beings that are created by the relationship between cultural inheritance and individuals, namely, through modernization and globalization processes. The immediate outcomes of these challenges and problems are ethnic conflicts, cultural clash and other cultural competitions. In order to maintain peace in the world and foster the mutual cooperation among the individuals, each individual has to be an active participant in the attainment of a sustainable development of the whole human system. The main focus of this paper, thus, is to analyze human behavior, as a way of understanding underlying powers of the interplay of biology and culture.
\end{abstract}

KEYWORDS: Inheritance system, evolution, development, inter-cultural relations

The river and its waves are one surf: where is the difference between the river and its waves? When the wave rises, is the water; and when it falls, it is the same water again. Tell me, Sir, where is the distinction?

Because it has been named as wave, shall it no longer be considered as water? Within the Supreme Brahma, the worlds are being told like beads;

Look upon that rosary with the eyes of wisdom. Kabir, II, 56 (translated by R. Tagore)

\section{INTRODUCTION}

The evolutionary perspective is one of the most innovative approaches in the international scene of social and behavioral sciences. Its principles stem from Charles Darwin's formalization of the paradigm of natural selection (Darwin, 1859). The basic concepts of evolution, selection and adaptation have been fruitfully applied to

* This article is republished with permission from the authors, which was published in In Pursuit of a Sustainable Modernisation: Culture and Policies in Nepal edited by Antonella Delle Fave and Min Bahadur Pun. The book was published in 2002 by Arcipelago Edizioni in Italy. - Editors 


\section{Crossing the Border: International Journal of Interdisciplinary Studies}

the analysis of human behavior, and several theories have been developed within the evolutionary framework. Sociobiology and evolutionary psychology emphasize the biological roots of individual and social behavior (Wilson, 1975; Barkow, Cosmides, \& Tooby, 1992). Bio-cultural theories underline the interplay of biology and culture, as two separate inheritance systems, in influencing individual behavior and development (Ruyle, 1973; Cloak, 1975; Boyd \& Richerson, 1985; Durham, 1982, 1991). A third approach is centered on psychological selection, that is the individual processing of bio-cultural information (Csikszentmihalyi \& Massimini, 1985).

In today's international context, the study of cultures, of their changes in time, of the relationship between cultural inheritance and individuals is not a mere academic exercise. Modernization and globalization pose a great number of challenges and problems to human beings. Ethnic conflicts, culture clash, and cultural competition have often had dramatic outcomes. The dominance of Western mono-cultural models disrupts ancient traditions. The spreading of free market and competitiveness strategy in economics exacerbates inequality and creates difficulties to developing countries. In this crucial phase of human history, any effort in this field of knowledge can contribute to promote a more peaceful and harmonious cohabitation of humans on earth.

\section{THE BIOLOGICAL INHERITANCE SYSTEM}

Homo Sapiens, like every other living species, shows biological features which are genetically inherited and transmitted from one generation to the next. They are the ultimate result of the natural selection process, first described by Charles Darwin. He assessed that the modifications arising in the biological traits of a species in time - in other words, the evolution of the species - are shared by the majority of the individuals in that they enhance individual fitness, i.e. the ability to survive and to successfully reproduce in a given natural environment. The conceptof fitness is closely related to adaptation: species evolve in that they acquire new and more adaptive traits which help individualsbetter cope with the requirements of the ecosystem they live in. In our species, the most remarkable emergent adaptive features have been:

- the development of the brain - especially the cortical components - which has provided humans with the so-called psychic superior functions. They allow us to develop abstract concepts, to perform complex quantification tasks, to plan our future and to use language as a highly articulated means of communication.

- the upright standing position, which frees arms and hands from supporting movement.

- the hand structure, which allows humans to perform fine and precise movements; thanks to the opposing position of the thumb to the other fingers.

\section{THE CULTURAL INHERITANCE SYSTEM}

By virtue of the above mentioned biological traits, humans started to manipulate the environment, to build artefacts, to create social norms, rules and roles. In one word, they created culture. This set of human products increased the adaptation of the species to the environment, and thus was implemented and expanded during the millennia. In time, culture has developed to such an extent that it can be considered as a second inheritance system. Ultimately, every humancommunity is much more influenced by the cultural inheritance than by the biological one. Bio-cultural theo- 


\section{CULTURAL CHANGE AND HUMAN BEHAVIOR ...}

ries have highlighted the basic evolutionary features of culture. Like biology, culture changes in time. Its basic unit of information has been defined as meme (Dawkins, 1976), analogously to the gene which is the replication unit of biology. There are however, some basic differences between the two replication units (Mundinger, 1980; Richerson \& Boyd, 1978).

The first difference concerns the storage of the information. Genes are carried by individuals, and spread by means of biological reproduction. On the contrary, memes can be stored in two different ways. They are primarily contained in the central nervous system of the individuals (the so-called intrasomatic culture, Cloak, 1975) as ideas, knowledge, experience, behavioral rules learned during not's life. Secondly, they are embedded in human artefacts: tools, books, buildings, art works, every object whichis not present in nature, but is the product of human activities. The storage of memes in extrasomatic carriers, beside human beings, has an important implication for the survival of culture. Genes cannot survive their carriers. Memes can. An entire human community may become extinct, but its books, buildings and artifacts can resists the vagaries of time and nature. Ancient Maya and Aztec societies have disappeared, but their pyramids, hieroglyphs and architectural structures tell us about their culture. Topsides lived several centuries ago, but his poems overcome the boundaries of time and space. Acupuncture was an ancient Chinese medical system, but now it is well known and used all over the world thanks to cultural transmission.

The second difference concerns the language used to transmit the information. Genes are coded in biological structures - namely DNA. Memes are translated into various codes: the natural languages, non-verbal behavior, the formulas of mathematics and physics, music, dance, ritual movements, images, material artefacts.

The third main difference between biology and culture lies in the pattern of transmissionof the information. Genes are passed on una tantrum, during biological conception. Memes can be communicated through non-verbal, oral and written transmission, and material artefacts throughout the whole life span of an individual. By virtue of this, cultural information can spread faster than genes: a single person can transmit it to several people at the same time (teachers, parents, writers, artists daily do it). With the improvement of technology and industrialization, the creation of objects has become faster, and it is possible to produce them in large amounts. Xerox machines can make thousands of copies of the same document. By means of assembly lines complex artefacts such as cars can be built quickly and in large quantities. On the contrary, physiological laws require a fixed amount of months to complete ontogenesis, and to give birth to a child as a new carrier of genes. Moreover, there is no limit to the number of memes individuals can acquire during their life. We can learn something new every day. We can virtually store in our brain networks a much larger amount of information than our average life span and physiological needs allow us to do.

The fourth difference concerns the creation of new information units. In biology, the main source of change is genetic mutation, which is a random, unpredictable, involuntary event. Moreover, modifications in gene's structure very often give rise to congenital pathologies, malformations, abnormal functioning, and precocious death of the individuals. Among all mutations which are produced through generations, only very few enhance the fitness of the carrier. This is the principle of biological inertia: a species does not easily modify its features. Adaptive changes are 


\section{Crossing the Border: International Journal of Interdisciplinary Studies}

rare contingencies, and millennia can go by without any improvement of fitness in a given species. This is at the same time the strength and the weakness of biological inheritance. Well adapted species show a genetic pool which enables them to resists the adversities of natural environment. But in case of rapid environmental disruption (glaciations, prolonged drought, and heavy climatic changes) their inertia could lead to extinction, as happened with dinosaurs and some other living systems on our planet. Also in culture new memes can arise randomly: but this is not the only pattern of mutation. Cultural information basically originates in the mind of people, as ideas, concepts, solutions to problems. Some of them can emerge in a casual way. This happened for the discovery of penicillin by Alexander Fleming. He studied bacteria, and one day he found out, with disappointment, that some of them died, attacked by mould. This was the first, unpredictable step toward the development of antibiotics. But in other situations a new meme can stem out of long preparation: an efficient engine is the product of many people working together to improve a previous, less powerful one. A new law derives from slow, subtle changes in the cultural habits which make it necessary to modify previous behavioral rules. This is for example the case of the provisions developed in this century in severalcountries to promote gender equality. Thus, cultural changes are often intentionally directed, and actively searched for, by humans. In this perspective, cultural inertia can be much lower than biological one. Moreover, cultural carriers themselves can decide to modify their memes through their voluntary effort.

\section{CULTURE EVOLUTION, CULTURE DEVELOPMENT AND INTER-CULTURAL RELATIONS}

The above described differences between culture and biology in the reproduction and transmission of information units highlight an important peculiarity of culture: its flexibility in respect with biology. Memes have more than one carrier, more than one receiver each time, more than one mechanism of change. They can be easily and quickly reproduced. Actually, humans have invaded the world with their artefacts. Whenever a community settles down in a geographical area, the natural environment undergoes more or less deep changes soon after. Modernization has pushed this process to an extreme point: in urban areas, the ecosystem is often heavily overwhelmed by the built environment.

The flexibility of memes provided humans with an extremely adaptive equipment. The biological weakness of our species has been overcome by means of artefacts. We do not have claws or strong teeth, but we have knives and weapons. We do not have furs, but we can make clothes. We cannot run fast, or jump high, or fly, but we invented wheels, chariots, cars, aeroplanes. Thanks to our ability to plan, to manipulate the environment, to formulate abstract theories, we could survive in every kind of ecological niche, from the Poles to the Equator.

According to the ecological niche, cultures differ: climactic conditions, sources of food, available raw materials gave rise to highly diversified societies. The differentiation of cultures plays the same role that the creation of new species and subspecies plays in biology: it improves flexibility and it increases the amount of information and survival strategies, which humans can adopt to cope with the environmental demands. This is a very important factor in the evolution of the living systems. Moreover, due to the modifications introduced in the ecosystem, culture becomes the 


\section{CULTURAL CHANGE AND HUMAN BEHAVIOR ...}

dominant environment where humans live. Parental cares mainly aim at transmitting to children the necessary memes which will allow them to properly behave in the social and cultural context. No other species requires such a long period of education to develop adaptive behavior. Human adaptation is only partially a biological matter: individuals have also to develop a cultural fitness, which is the most important resource they need to cope with environmental challenges.

The emergence and unfolding of different cultures generate a unique phenomenon among humans: diversity of intra-specific communication. Two individuals raised in different cultures, however belonging to the same species, can often hardly understand each other. Languages, habits, beliefs, social structures show great diversity. Inter-cultural relationships thus have to develop when two or more human communities get into contact. This seems to be one of the most problematic tasks our species has to accomplish.

Contact among cultures substantially means comparison of the basic social norms, habits and values each community is built on. An analysis of the sets of norms belonging to different cultures has been conducted by studying the Constitutions of Western and Non-western countries (Calegari \& Massimini, 1978; Massimini \& Calegari, 1979). Constitutions represent sets of cultural information which regulate individual and group behavior within cultural contexts. They also comprise the basic values of a social system that can be broadly defined as the goals and standards of behavior which are desirable for the individual and for the group in a specific cultural context (Rokeach, 1974; Calegari \& Massimini, 1976; Schwartz \& Bilsky, 1987). The above mentioned analysis showed the recurring presence of 11 fundamental groups of norms, which were treated as units of a 'Cultural Network'. Each unit deals with a major problem that society has to solve in order to survive culturally and reproduce in time. The units can be grouped into four categories, according to the issues they deal with: 1. bio-cultural reproduction (Work, Property, Income), 2. cultural reproduction (Education, Information Exchange, Participation, Decision Making), 3. prescription (Legal system, Status), 4. evaluation and justification (Individual values, Social Values). The whole set of units has been defined 'network' because its elements interact with one another, and are connected by mutual influences. For example, the availability of formal education programs for all citizens, or for only a part of them, will influence individuals' status, occupation, decisional power within the group. In each culture, different specific solutions to the issues represented by the network units will be developed according to the peculiarities of its history. Moreover, each culture will set forth different priorities for the goals to be pursued. For example, a given population can attribute more relevance to the distribution of wealth than to the educational level. In another case, the affiliation to a religions group can give to the individuals more prestige than economic status. Cultural networks have been detected in written Constitutions, as well as in orally transmitted instruction sets, like the one in use among the Papua Kapauku of Western New Guinea (Massimini, 1982).

This kind of studies poses a key dilemma to the researcher, and to the field workers dealing with inter-cultural relationships. How can we evaluate the "superiority" of a culture, or the higher desirability of a value system, in comparison with another one? This is not an academic question. The history of mankind is characterized by cultural contacts which only rarely have been co-operative, more often resulting in conflict and cultural competition. Some cultures survived to the detriment of others, 


\section{Crossing the Border: International Journal of Interdisciplinary Studies}

some cultures subjected others, and some cultures imposed their value system to others. Is there any matter of superiority and higher desirability in the outcomes of these conflicts?

In order to deal with this thorny issue, we have to briefly analyze the evolutionary trend every culture undergoes in time. Like in biology, within a cultural context some information is selectively transmitted across generations, some other becomes extinct in that it proves to be unfit for the survival in that environment. Like biological evolution, cultural evolution is a process of change in neutral terms: change, per se, does not necessarily mean improvement, but fitness enhancement. As pointed out by several researchers (see Diamond, 1997, for a historical review) some cultures underwent dramatic changes in time by virtue of the adoption of agriculture and of a sedentary lifestyle. This gave rise to the division of labor, to the differentiation of skills, to the advancements in technology, to more articulated patterns of social organization, and to a more systematic codification of cultural information. Thanks to these changes, some cultures became better equipped to cope with environmental demands, in that they showed a higher flexibility, and more and more specialized strategies and tools to face any kind of difficulties. But this is very different from saying that their memes were "better" than the ones reproduced by other societies.

The dominance relationship among cultures has traditionally been rooted in the level of sophistication of the artefacts. More specifically, the development of technology was - and is nowadays - the key factor influencing the chances a culture has to win a war, to spread its values, to colonize other populations. This process has imposed a specific evolution trend to the human communities living on earth. Technological artefacts and various techniques gradually dominated the world throughout history, until the most recent manifest spreading of modernization. In the last centuries some cultures - mainly the Western technological ones - have been prevailing because of their adaptive traits, i.e. ability to survive and successfully reproduce, and not because their memes and values are absolutely better or ethically more desirable than others. Far from being grounded in ethical principles, the real power of a country is based on the efficiency of its artefacts, be they weapons, computers, or industrial machines. This has caused the extinction of many human societies in the millennia. Today we can sadly hear the swan song of previously numerous and complex cultures: Aboriginal populations in Australia, Native Americans, Tribal groups in Asia and Africa, suffocated by the relentless advance of Western values and objects.

After this very concise excursus we could draw the conclusion that cultural evolution, like the biological one, is a blind process. Like genes, memes are submitted to the principle of "survival of the fittest," regardless of the consequences in terms of ethics or human values. This should be held true as concerns both the evolution of a single culture, and the contact among cultures.

The events of human history apparently confirm this alarming conclusion. The frequent occurrence of wars, the devastating effects of pollution on the ecosystem, the increasing power of virtual reality on concrete necessities, the primacy of cultural manipulation on biology with no concern about the consequences can be valid examples of the blindness of cultural evolution process. The dominant utilitarian principles in economics have contributed to sharpen inequalities, instead of promoting welfare around the world (Sen, 1986). The manipulation of grain, rice and vegetables' 


\section{CULTURAL CHANGE AND HUMAN BEHAVIOR ...}

DNA is generating serious problems to the farmers of developing countries, instead of helping avoid famines. The abuse and misuse of antibiotics has given rise to resistant bacteria, which cause previously unknown illnesses. The growing dependence upon electric supply provokes the complete paralysis of whole cities, hospitals, schools, house equipment in case of black-out. Life is easier, but human species is becoming less and less able to survive without artefacts. Earth resources are not limitless. Nevertheless, the process of artefacts' expansion seems inexorable.

But there are alternative strategies to the blind evolution of culture. Any meme is first generated in the individual mind, and human beings have the ability to make plans, set goals, and intentionally intervene to correct cultural mistakes.

The introduction of new memes, in order to be defined as positive, has to enhance the complexity of a culture, i.e. it has to improve the connections and integration among the various parts and components of the culture, considered as a dynamic living system (Massimini \& Delle Fave, 1991; Delle Fave \& Bassi, 1998). Moreover, fitness can be pursued by means of complexity. The problem is that the two processes do not necessarily coexist: enhancement of fitness can also be produced by reducing memes' number and integration in a given culture.

This can be better clarified by means of few examples. As concerns a typical process of cultural change, namely modernization, Native American tribes in several cases were forced to abandon their beliefs, values and skills and to adopt modernized ones in order to survive in the Western environment. However, their culture got impoverished, instead of being enriched. Native Americans mostly faced marginalization within the affluent white men's society. In many traditional cultures, local healers are able to successfully treat back pain, allergies, psychiatric syndromes, various other kinds of disease. The irruption of Western medicine frequently wiped out this precious corpus of knowledge, and substituted it with pills that only temporarily reduce pains and complaints, but donot solve the basic problem. This is again a case of simplification in culture.

The ability to preserve original traditions and, at the same time, to introduce new information is the best strategy to maintain flexibility and increase complexity in a cultural system (Delle Fave \& Massimini, 1999). Among the different patterns of interaction between cultures, this strategy has been labeled cultural integration (Berry \& Sam, 1997) or biculturalism (Delle Fave, Massimini, \& Maletto, 1991; La Fromboise, Coleman, \& Gerton, 1993). It allows a culture to successfully cope with environmental changes, thanks to the introduction of new memes and their reintegration with the already existing ones.

The emergence of cross-cultural studies in most disciplines has given impulse to a growing awareness about the precious cultural resources of traditional societies. This is a little conquest of the second half of this century. Moreover, it is a little step toward enhancement of complexity in human culture, in that it promotes a fruitful exchange of information. Co-operation and reciprocity between social systems, rather than conflicts, foster the cultural evolution process in its constructive meaning. But the process is at its very beginning, and it is not strong and spread enough to stop the process of homogenization of cultures in compliance with Western standards.

As concerns modernization in developing societies, one of the most important achievements has been the recent attention paid to strategies 'sustainable development'. As stated at the Earth Summit in Rio de Janeiro (1992) and quoted in Mitchell 


\section{Crossing the Border: International Journal of Interdisciplinary Studies}

(1994) "Sustainable development does not imply any single pattern of development and environmental management, but rather each country, region and people will develop distinctive ways to achieve it" (p. 189). The numerous mistakes consequent to the imposition of Western standards have shed light to the importance of the implementation of local resources and local knowledge for the sake of cultures' authentic improvement. The so-called CBR groups (Community Based Resources) have developed in Asian, African and South American countries. They promote and realize advancements and intervention programs in the fields of employment, welfare distribution, health care and prevention, disability, education. Their main resources are the competence and know-how of community members, and they are financially supported by the community itself, by local and international non-governmental organizations (NGOs), and by local governments. The main inspiring principle of CBRs is that a sustainable cultural development has to start from the efforts of the community, from the local awareness of priorities and from the choice of intervention strategies coherent and well suited to the local cultural background.

\section{INDIVIDUAL PSYCHOLOGICAL SELECTION}

The importance of culture in human species can be evaluated at the individual level. Children receive a double inheritance: the biological one genetically transmitted by their parents, and the cultural one, absorbed from the social environment by means of learning. However, individuals are not simply vehicles of genetic and cultural information. They are also active agents. Day by day, and throughout their life span, they select and reproduce a limited number of information units within their cultural pool (activities, interests, political and moral beliefs). This is especially true of highly articulated societies, where people specialize in jobs, areas of education, personal interests. This process of selection can be imposed by culture itself. For example, in theocratic societies, individuals are forced to follow only the dominant religious system. In strictly stratified groups, people have access to only few jobs, according to the class they belong to. In case of gender stratification, women are usually restrained from getting involved in activities, interests and professions which are considered males' domain.

However, if we exclude the most extreme conditions, the person always has a more or less wide range of alternative activities to be engaged in during her life. We again deal with a process of selection - like in biology and in culture - which takes place at the psychological level. People differentially reproduce memes in their daily life. A great number of cross-cultural studies have been conducted in this field, in order to detect the basic criterion which guides psychological selection (Csikszentmihalyi \& Massimini, 1985; Massimii, Csikszetmihalyi, \& Carli, 1987; Massimini, Csikszentmihalyi, \& Delle Fave, 1988). A major role is played by the quality of experience people associate with the activities, social contexts, situations - in one word, memes - they come into contact with. Human beings get involved in and preferentially reproduce situations and activities connected with a peculiar state of consciousness, labeled as 'Optimal experience' (Csikszentmihalyi, 1975, 1978; Csikszentmihalyi and Csikszentmihalyi, 1988). Optimal experience is characterized by high levels of concentration, focusof attention, and involvement in the task at hand. People report positive mood, clear goals, unselfconsciousness, and intrinsic motivation (they perform the activity for its own sake, regardless of external rewards, see Deci \& 
Ryan, 1985). They also perceive high challenges in the situations, and adequate levels of skills to face them. This experience is complex and highly positive. It plays a key role in the developmental path of individuals. The psychological selection of memes through optimal experiences is the basis for the uniqueness of each individual in the social group. Like biology and culture, it is an evolutionary process, and therefore it brings changes in behavior.

As happens for the other two systems, the evolution trend supported by psychological selection does not necessarily lead to and improvement of the person's behavior. The ultimate result depends upon the type of activities an individual decides to reproduce in her life. Development means growing complexity also at the psychological level: to bring positive effects, evolution has to promote internal order and integration of the individual, and at the same time constructive information exchange with the environment. The outcome of an authentic development at the psychological level is a creative and satisfied person, who is at the same time well integrated in the social environment and committed to the improvement of the cultural system she belongs to.

\section{THE ROLE OF INDIVIDUALS IN CULTURAL DEVELOPMENT: EXAMPLES FROM NEPAL}

Biological traits and cultural inheritance influence individual behavior. At the same time, psychological selection influences the replication and transmission of only some of the cultural and biological units. As regards culture, therefore, individuals play a main role in orienting its evolution, and they can actively promote changes which enhance the complexity of the cultural system. Thus, in human communities, the central responsibility of each member in the building of the future society should become one of the basic concepts to highlight. Young people should be more clearly taught the potential consequences at the cultural level of their behavior and choices at the personal level.

This awareness, and the positive implication of it, characterizes the intervention of several Nepalese non-governmental organizations. As we discussed above, memes' change occur through individual psychological selection. Cultural norms, habits and beliefs are learned throughout life, and they are reproduced and transmitted across generation by means of individuals' psychological selection. Thus, the amount and quality of attention parents, teachers and educators devote to the transmission of cultural instructions, and the kind of information transmitted will eventually influence the cultural selection process. At present, one of the basic principles to build an effective intervention is to consider end users themselves as the core agents of social change, encouraging them to follow their intrinsic motivation and to select the environmental opportunities according to the associated quality of experience, and thus supporting individual development.

Very often in developing countries, intervention protocols and rehabilitation programs are based on Western models, thus being completely unrelated to local cultures. As illustrated in the previous pages, the arbitrary introduction of unrelated new memes in a cultural system has very low chances of success, and it can even cause disruption in the local culture. Examples from the involvement of end users - be they street children or disabled youth - in daily routine tasks, traditional work, religious practices, meditation, art and handicraft training, all of them belonging to 


\section{Crossing the Border: International Journal of Interdisciplinary Studies}

the cultural pool of information individuals have been raised in.

In order to bring substantial changes in the conditions of people suffering from any kind of people suffering from any kind of marginalization, the surrounding community has to be aware of their rights and needs and it has to actively co-operate for the improvement of their life. Differently from most social assistance interventions, the Nepalese projects illustrated in the following chapters are centered on the active enrolment of families and communities. This has important evolutionary implications. In order to be broadly replicated, cultural instructions have to be shared by the majority of the society members. With their role as selective agents and transmitters of information, individuals have the power to influence the survival or elimination of culture units. The combined action of various "psychological selectors" can foster cultural change in terms of social construction and improvement.

Finally, in order to be effective and long lasting, cultural change should not undermine the system's stability in the short run. On the contrary, it should enhance inner integration and complexity of the system itself. In biology emergence of a new species is a slow, gradual, time requiring process, eventually giving rise to a new organism, well equipped to face environmental challenges and only exceptionally undergoing short term extinction. The same principle can be applied to cultural evolution process, and it should be one of the pillars of any intervention program.

\section{CONCLUSIONS}

While evolution is blind and based on fitness enhancement, development should be far sighted and targeted at the improvement of complexity. A complex system is an improbable and delicate entity, and its survival depends on the correct and harmonious functioning of all its components. Each individual in the world is a small, but active member of mankind. Cultures are intermediate aggregations of individuals, and their mutual co-operation is the only hope to foster a sustainable development of the whole human system. Until this simple and obvious principle is not made clear to each of us, inequality, conflict and confrontation will interfere with the actualization of the complexity potential our species has been equipped with.

\section{REFERENCES}

Barkow, J. H., Cosmides, L., Tooby, J..(1992). The adapted mind: evolutionary psychology and the generation of culture. New York: Oxford University Press.

Berry, J. W., Sam, D. L. (1997). Acculturation and adaptation. In Berry, J. W., Segall, M. H., Kagitcibasi, C. (Eds.). Handbook of Cross-Cultural Psychology, Vol.3: Social Behaviour and Applications, 291-32. Needam Heights, MA: Allyn \& Bacon.

Boyd, R., Richerson, P. J. (1985). Culture and the evolutionary process. Chicago: Chicago University Press.

Calegari, P., Massimini, F. (1976). Introduzione alla teoria del valori umani. Milano: ISEDI.

Calegari, P., Massimini, F. (1978). Psicologia dell'artefatto normativi sociale. Milano: Franco Angeli.

Cloak, F. T. (1975). Is a cultural ethology possible? Human Ecology, 3, 161-182.

Csikszentmihalyi, M. (1975). Beyond boredom and anxiety. San Francisco: Jossey Bass. 


\section{CULTURAL CHANGE AND HUMAN BEHAVIOR ...}

Csikszentmihalyi, M. (1978). Attention and the holistic approach to behavior. In Pope K. S. and Singer J. L. (eds.). The stream of consciousness, 335-358. New York: Plenum.

Csikszetmihalyi, M., Csikszetmihalyi, I. (Eds.). (1988). Optimal experience. Psychological studies of flow in consciousness. New York: Cambridge University Press.

Csikszentmihalyi, M., Massimini, F. (1985). On the psychological selection of biocultural information. New Ideas in Psychology, 3, 115-138.

Darwin, C. (1859). On the origin of species by means of natural selection. London: Murray.

Dawkins, R. (1976). The selfish gene. Oxford: Oxford University Press.

Deci, E. L., Ryan, R. M. (1985). Intrinsic motivation and self-determination in human behaviour. New York: Plenum Press.

Delle Fave, A., Bassi, M. (1998). Esperienza di flow e sviluppo dellacomplessita nel comportameto umano. Informazione in Psicologia, Psicoterapia, Psichiartia, 32/33, 32-47.

Delle Fave, A., Massimini, F. (1999). Inter-cultural relations: A challenge for psychology. In Delle Fave, A., Meli, F. (Eds.). Modernization and Cultural Identity. Milano: Edizioni Dell' Arco.

Delle Fave A., Massimini F., Maletto C. (1991). Processi di modernizzazioe e selezione biculturaleumana, in Inghilleri P., Terranova Cecchini R. (Eds.). Avazamenti In Psicologia Transculturale. Nuove Frontier Della Cooperazione, 99-137. Milano: Franco Angeli.

Diamond, J. (1997). Guns, Germs, and Steel. The Fates of Human Societies. New York: W. W. Norton \& Co.

Durham, W. H. (1982). Interactions of genetic and cultural evolution: models and examples. Human Ecology, 10, 289-323.

Durham, W. H. (1991). Coevolution. Genes, culture and human diversity. Stanford, CA: Stanford University Press.

La Fromboise, T., Coleman, H. L. K., Gerton, J. (1993). Psychological impact of biculturalism: evidence and theory. Psychological Bulletin, 114, 395-412.

Massimini, F. (1982).Individuo, cultura, ambiente: i Papua Kapaukudella Nuova Guinea Occidetale. Ricerche di Psicologia. 22-23, 27-154.

Massimini, F., Calegari, P. (1979). Il contest normativo sociale. Milano: Angeli.

Massimini, F., Csikszentmihalyi, M., Carli, M. (1987). ESM and the monitoring of optimal experience: a tool for psychiatric rehabilitation. Journal of Nervous and Mental Disease, 175, 545-549.

Massimini F., Csikszetmihalyi M., Delle Fave A. (1988). Flow and Biocultural Evolution. In Csikszetmihalyi M., Csikszetmihalyi I. (Eds.): Optimal experience. Psychological Studies of Flow in Consciousness, 60-81. New York: Cambridge University Press.

Massimini F., Delle Fave A. (1991). Religion and cultural evolution. Zygon, 1, 27-47.

Mitchell, B. (1994). Sustainable development at the village level in Bali, Indonesia. Human Ecology, 22, 189-211.

Mundinger, P. C. (1980). Animal culture and a general theory of cultural evolution. Ethology and Sociobiology, 1, 183-223.

Richerson, P. J., Boyd, R. (1978). A dual inheritance model of human evolutionary process: basic postualtes and a simple model I. Journal of Social and Biological 


\section{Crossing the Border: International Journal of Interdisciplinary Studies}

Structures, 1, 127-154.

Rokeach, M. (1974). The nature of human values. New York: Free Press.

$\backslash$ Ruyle, E. E. (1973). Genetic and cultural pools: some suggestions for a unified theory of biocultural evolution. Human Ecology, 1, 201-215.

Schwartz, S. H., Bilsky, W. (1987). Toward a theory of the universal structure and content of values: extensions and cross-cultural replications. Journal of Personality and Social Psychology, 58, 878-891.

Sen, A. (1986). On ethics and economics. New Delhi: Oxford University Press.

Tagore, R. (1915). One Hundred Poems of Kabir, translated from Sri Kshiti Mohan Sen, 4 parts, Brahmacharyashrama, Bolpur, 1910-11. Reprint 1997. New Delhi: MacMillan India Ltd.

Wilson, E. O. (1975). Sociobiology: The new synthesis. Harvard Mass.: Bellknap.

\section{ABOUT THE AUTHORS}

Antonella Delle Fave, MD, is Professor of Psychology at the Medical School, University of Milano, Italy. She conducted several cross-cultural studies on the process of psychological selection and the quality of experience in daily life. Email: antonella.dellefave@ unimi.it

Fausto Massimini, MD, is Professor of Psychology at the Medical School and Chief of the Department of Preclinical Sciences LITA Vialba, University of Milano. He is author of theoretical and empirical studies on the relationship between individual behaviour and bio-cultural inheritance. 